\title{
2. A Complex Kind of Training: Cities, technologies and sound in jazz-age Europe
}

\section{James Donald}

Writing in the 1920s, Robert Musil opens his novel The Man Without Qualities by evoking Vienna in the final days before the Great War changed everything. His visual imagery recalls contemporary experiments in abstract and rhythmic film-making by Walther Ruttmann, Hans Richter or Viking Eggling. Blocks of light and shade are cross-cut by lines in motion - speeding automobiles in Musil's case - while the movement of pedestrians negotiating their way through the city's streets creates more fluid, fractal patterns. The way Musil 'hears' the city, however, is more ambivalent and less assertively modernist. His 'wiry texture' of sound shares the jagged angularity and dynamism of the visual images, but the way in which he then anchors this particular soundscape to Vienna seems to hark back to an earlier, more traditional aesthetic that assumed sound to be characteristic of, and specific to, place. ${ }^{1}$

It was a fine day in August 1913.

Automobiles shot out of deep, narrow streets into the shallows of bright squares. Dark clusters of pedestrians formed cloudlike strings. Where more powerful lines of speed cut across their casual haste they clotted up, then trickled on faster and, after a few oscillations, resumed their steady rhythm. Hundreds of noises wove themselves into a wiry texture of sound with barbs protruding here and there, smart edges running along it and subsiding again, with clear notes splintering off and dissipating. By this noise alone, whose special quality cannot be captured in words, a man returning after years of absence would have been able to tell with his eyes shut that he was back in the Imperial Capital and Royal City of Vienna. Opening his eyes, he would know the place by the rhythm of movement in the streets long before he caught any characteristic detail. It would not matter even if he only imagined he could do this. ${ }^{2}$

Had this imagined exile returned 10 years later-when Musil was writing - would the sound of the city still have identified it so immediately and unchangingly as Vienna and nowhere else? And would our exile, with eyes shut or wide open, have listened to the city in the same way? It is doubtful. He would now have found himself in Red Vienna, struggling to recreate itself in the straitened aftermath of war and revolution, rather than in Imperial and Royal 
Vienna in its final spasms of self-deluding pomp. The purr and jangle of ostentatious wealth and the brassy folies de grandeur of autocratic power would to a large degree have been silenced. More striking would have been the noisy business of building a liveable social democratic city, and the sounds of a city opening up to more demotic, international and commercial forms of culture and communication. Vienna's particular political make-up, its demographic changes, the speed of its economic recovery, the particular emphasis on building workers' housing and constructing a social infrastructure, the density of public and private transport, the new types of leisure and entertainment venues to be offered to the public and the emergence of new media technologies - all these factors, and others, would have combined to produce a distinctive mix that would have made the city still sound different from Berlin, Paris or London. Equally, however, new sounds associated with social changes were increasingly common to all these cities, and so their soundscapes were inevitably becoming more and more similar. Perhaps as a result, the idea of sound as the acoustic genius of a place was giving way increasingly to the idea of noise as an intrusive and wiry-textured aspect of the urban environment that needed to be measured, managed and controlled.

This new, more modernist style of listening becomes dominant as Musil switches the emphasis of his narration from the uniqueness of Vienna's historical soundscape to its modern typicality:

So let us not place any particular value on the city's name. Like all big cities it was made up of irregularity, change, forward spurts, failures to keep step, collisions of objects and interests, punctuated by unfathomable silences; made up of pathways and untrodden ways, of one great rhythmic beat as well as the chronic discord and mutual displacement of its contending rhythms. All in all, it was like a boiling bubble inside a pot made of the durable stuff of buildings, laws, regulations, and historical traditions. ${ }^{3}$

The sociological imagination behind these metaphors is still that of Georg Simmel, whose 1903 essay, 'The Metropolis and Mental Life', had not only prefigured Musil's theme of the loss of 'qualities' (or the individual, subjective characteristics Simmel termed 'personality'), it had offered an explanation for the phenomenon. 'The individual,' wrote Simmel, 'has become a mere cog in an enormous organisation of things and powers which tear from his hands all progress, spirituality, and value in order to transform them from their subjective form into the form of a purely objective life.' What he calls the 'overwhelming fullness of crystallised and impersonal spirit' is identical to Musil's 'durable stuff of buildings, laws, regulations, and historical traditions' ${ }^{4}$ The difference between the two accounts lies in the novelist's ability to convey what the implosion of 'personality' felt like by presenting an almost synaesthetic conflation of the 
social with the sensory - with vision and movement, but also with hearing and sound. Modernity in Vienna was experienced as cacophony and syncopation: 'the chronic discord and mutual displacement of its contending rhythms.'

Simmel's pupil Walter Benjamin also tried to capture the somatic or sensory level at which people felt and adapted to the rhythms of a changing world. In Charles Baudelaire: A Lyric Poet in the Era of High Capitalism, he distinguishes between Poe's nineteenth-century 'Man of the Crowd' and the contemporary pedestrian whose habits of looking, seeing and movement have been changed by the development of motor traffic and even by the traffic signals that first appeared in Berlin's Potsdamer Platz in 1926.

Moving through [the traffic of a big city] involves the individual in a series of shocks and collisions. At dangerous crossings, nervous impulses flow through him in rapid succession, like the energy from a battery. Baudelaire speaks of a man who plunges into the crowd as a reservoir of electric energy. Circumscribing the experience of the shock, he calls this man 'a kaleidoscope equipped with consciousness'. Whereas Poe's passers-by cast glances in all directions which still appear to be aimless, today's pedestrians are obliged to do so in order to keep abreast of traffic signals. Thus technology has subjected the human sensorium to a complex kind of training.

The question here is how in the post-World War I period technology subjected the sense of hearing and the practice of listening to this complex kind of training. It is not just that people were hearing new sounds - often sounds made by machines, and sometimes machines designed to produce sound. As the second quotation from Musil suggests, people were also beginning to think about hearing in new ways. ${ }^{5}$

Although I emphasise the new ways of hearing described and enacted by writers and musicians, the early decades of the twentieth century were a time when scientists and technologists were also rethinking the mechanics and meaning of sound along similar lines. Acousticians in the 1920s would have thought about the link between sound and a specific place less in terms of the audible character or aural experience of a place-Musil's exile returning to hear an unmistakable Vienna, for instance - than in terms of the reverberation that constitutes the acoustic signal of a particular space or place. And they would have thought of it as a problem insofar as it was seen as an impediment to the clarity of sound as signal or information. The aim was to make sound clear, direct and functional. This meant making it less reverberant, thus divorcing sound from place and making spaces sound increasingly alike. This principle applied equally to the emerging technologies for the reproduction of sound: the telephone, the gramophone and radio. Here again the aim was efficiency: faithfulness in reproducing an inevitably fuzzy and unfocused original was less important that 
stripping the reproduced sound of extraneous noise and interference so that a hearer or listener could easily decode and understand it. ${ }^{6}$

\section{The machine age}

In his documentary novel, The Life of the Automobile (1929), Ilya Ehrenburg describes the sounds of the Citroën factory outside Paris in a way that harks back to Simmel's image of the individual as a cog, forward to Charlie Chaplin's satire on the assembly line in Modern Times and tangentially to the concerns of acousticians.

The Citroën works had twenty-five thousand employees. Once, they had spoken different languages. Now they kept silent. A close look revealed that these people came from different places. There were Parisians and Arabs, Russians and Bretons, Provençals and Chinese, Spaniards and Poles, Africans and Annamites. The Pole had once tilled the soil, the Italian had grazed sheep, and the Don Cossack had faithfully served the Tsar. Now they were all at the same conveyor belt. They never spoke to one another. They were gradually forgetting human words, words as warm and rough as sheepskin or clods of freshly plowed earth.

They listened to the voices of the machines. Each had its own racket. The giant drop-hammers boomed. The milling machines screamed. The boring-machines squealed. The presses banged. The grinding-lathes groaned. The pulleys sighed. And the iron chain hissed venomously.

The roar of the machines deafened the Provençals and the Chinese. Their eyes became glassy and vacant. They forgot everything in the world: the color of the sky and the name of their native village. They kept on tightening nuts. The automobile had to be noiseless. Engineers sat and thought. How could they build a mute engine? These valves had to be silenced. The buyer was so nervous! The men along the belt had no nerves. They only had hands: to tighten a nut, to fasten a wheel. ${ }^{7}$

This passage brings together a number of features in the modern soundscape. First, and most obvious, there is the brutal, deafening sound of the machinery of mass production. This is what people working in factories would have heard. Second, however, the passage connotes ways of thinking about the fact that these workers were being subjected to this deafening and deadening environment. There is Ehrenburg's Marxist critique, in which the only concern for noise reduction is aimed at assuaging the sensitive ears of bourgeois car-buyers. In fact, as Ehrenburg implies, noise at this time was being seen increasingly as a problem in need of technical solutions - and for reasons rooted in the production process as well as in consumer culture. Excessive noise was recognised as a health hazard needing treatment by physicians, and one that could indeed have a negative impact on the productivity of workers. Engineers 
and technologists were therefore developing new electro-acoustical instruments to measure and quantify sound with a view to mitigating its undesirable side-effects. Thirdly, there were increasing efforts to act on the material and social causes of noise. As noise pollution became an issue, noise abatement emerged as a significant progressive and/or conservationist political cause, engineers sought ways to make machines quieter and architects paid unprecedented attention to sound proofing and the acoustic design of buildings. Such problems, and the solutions being sought to them, reinforced the sense of noise as something independent from time and space, as decontextualised signals hitting the ear rather than the sort of unique audible dimension of a place that Musil heard in Vienna.

Ehrenburg's description of Citroën's workforce adds a fourth element, which can be found in many contemporary accounts of the soundscape of the 1920s. This is the image of the modern metropolis as the new Babel, as the number of languages to be heard in the European capitals multiplied. Here, Ehrenburg lists this linguistic diversity only to note how it is silenced, drowned out by the desensitising machines. In doing so, he is pointing to a paradox of capitalist development. The type of mass production represented by Citroën acted as a magnet for people, attracting them from around the world to the great industrial centres of Europe and America. As it did so, however, it obliterated their specific differences - as it also tended to do through its colonising appropriation of large parts of the globe.

The themes of migration, standardisation and atomisation again recall Simmel's account of the impact of the modern metropolis on subjective life. The overload of external information and stimuli in the modern metropolis, he believed, had provoked a new armouring of the modern self evident in a blasé attitude towards others and a purely aesthetic individualism. That adaptation of metropolitan stimuli to the ends of self-creation can be seen in the embrace of Berlin's noise and mechanisation by the novelist Alfred Döblin, author of Berlin Alexanderplatz: 'The city as a whole has an intensely inspiring, energizing power; this commotion of the streets, shops and vehicles provides the heat I must have in order to work, at all times. It is the fuel that makes my motor run.'

The defensive response, in contrast, is exemplified tellingly in a 1926 article, 'The Blue-Black Rose', by the philosopher and social critic Theodor Lessing. He found modern Berlin just too noisy: 'I hate the cries of the street merchants and newspaper vendors. I hate the ringing of the church bells, I hate the senseless noise of the factory sirens, but what I hate most are the stinking autos.'

For Lessing, as for Schopenhauer with his diatribes against the infernal cracking of whips in the nineteenth century, the sounds of the city and its machines represented something worse than an intrusion on his right to privacy. Their noise destroyed the silence necessary for inner reflection, thought and so 
self-development and artistic or intellectual creation. Driven to distraction, Lessing fantasised desperate measures.

Banish the 'symbols of culture' from the thoroughly wired landscape, filled with advertisements and smokestacks; perhaps one site will remain holy and unspoiled. I've decided to steal a pocketwatch at some point - with the hope of being arrested. In prison I will at least have peace from the rug beating, the piano playing, the car horns, the gramophones, and the telephones.

In his irritation and distraction, Lessing does not discriminate between different kinds of noise: long familiar interruptions such as church bells, rug beating and piano playing, the side-effects of modernisation such as factory sirens and cars with their horns, and machines designed specifically to produce sound as a means of communication (such as the telephone) or a commodity (such as the gramophone). He therefore fails to notice, or to address, what Benjamin saw in technologies such as the telephone or gramophone. They did not simply disrupt old habits of perception and selfhood; through their complex training of the senses, they reconfigured ways of relating to oneself, to others and to the world.

As many historians and critics have observed, a key feature of this modern experience was a new dynamic of time, space and presence, the transcendence of distance. Looking back on the achievements of his fellow acousticians in 1929, for example, Harold Arnold, a physicist who had helped to develop techniques that improved the sound quality in telephones, radios and gramophones, declared: 'Now with one broad sweep the barriers of time and space are gone. ${ }^{8}$ The new machines created the possibility of virtual communication: talking to people not physically present, for example, or hearing music recorded long ago or far away. This world-shrinking and experience-expanding capacity of radio is invoked by Ehrenburg in an early section of The Life of the Automobile to frame his portrait of the first man to be killed in an automobile accident in France. The victim is presented as addicted fatally to the new experiences offered by new machines and technologies - not just radio, as here, but automobiles and cinema.

Then a new serpent moved into his home. It hissed sweetly. It was the radio. Bernard's days still had an appearance of well-being. But at night he went crazy. He wore warm slippers with pompoms. But he wasn't sitting at his fireplace; no, he was whizzing through the world. His lips moved suspiciously. He was looking for waves. Here was Barcelona...Here was Karlsruhe... The German word 'bitte.' Bach. Spaniards. A charleston. The winner of the race at Oxford. The Royal Dutch rates. An Italian lesson: forte, morte, cannelloni. The victory of the Conservatives in Sweden. The bells of the Kremlin: The Internationale. Another charleston. The world moohed, bleated, meowed. 
The 1920s were the decade of radio. The British Broadcasting Company (BBC) began its broadcasts from Savoy Hill on the evening of 17 September 1922, to be followed on 6 November by the first private radio transmitter in France - called initially Radiola but soon renamed Radio Paris - and then a year later, on 29 October 1923, by the Vox record company's broadcasts from Berlin. Ehrenburg seems to have been right to stress the cosmopolitanism of the content - a cosmopolitanism born largely of necessity, as radio stations were forced to broadcast whatever appropriate material they could lay their hands on. Here is the Illustrated London News's description of the type of listening offered in the BBC's earliest days: an afternoon concert from the Eiffel Tower, a Tuesday evening concert from the Marconi works at Chelmsford, Thursday evening concerts from the Hague and the Sunday afternoon 'Dutch concert'. 9 The mastery of nature and the annihilation of time and space celebrated by Harold Arnold were not, however, just technical breakthroughs. The ability of film to bring images of the world to a cinema near you and the power of radio to make sounds from around the world available to you in your home-dressed, if you liked, in your slippers with pompoms - were major factors in the appeal of the two media. They seemed to promise a new universalism transcending differences of language and culture.

Radio was not just cosmopolitan in its content. It also created a new audience, a new community, that was at least potentially universal in the sense that, however widely scattered it may have been across cities and nations, it was nonetheless linked together in time 'with a simultaneity that made physical travel seem antediluvian by comparison'. ${ }^{10}$ Paradoxically, however, this experience of hearing the world in your living room did not lead to more extensive or less constrained communication. Instead, it made people conscious that where they happened to live was not the world, but one place in an increasingly complicated and mysterious world. It emphasised the atomisation and aesthetics of defensive self-creation diagnosed a couple of decades earlier by Simmel. The virtuality of radio also added an uncanny dimension to the objectification of modern life; a sense of placelessness as everyday experience was mediated increasingly through the sounds and stories carried electronically through the air. In 1928 Berlin, Mischa Spoliansky and Marcellus Schiffer wrote a song, Es liegt in der Luft (There's Something in the Air), which captures something of the novelty and the paradox of this new media environment. First, they notice how telephone, radio and cinema 'informationalise' culture, turning it into something like electricity, into signals even more than signs.

There's something in the air called objectivity (Sachlichkeit),

There's something in the air like electricity...

But then they go on to conjure up the disconcerting, incredible barrage of sounds and images being carried by those signals. 
What has come over the air these days?

Oh, the air has fallen for a brand new craze.

Through the air are swiftly blown

Pictures, radio, telephone.

Through the air the whole lot flies,

Till the air simply can't believe its eyes.

Planes and airships, think of that!

There's the air, just hear it humming!

Trunk calls, Trios in B flat

In the gaps that are left a picture's coming.

This was a strange and confused new world, an immaterial yet compelling soundscape populated by mechanically reproduced voices and sounds that changed the very nature of subjective being. 'As society becomes progressively aestheticized,' writes Michael North, 'as audiences begin to consume imaginative and symbolic materials as they had previously consumed material goods, then everyday life acquires an inherently ironic distance from itself.'11

Marcel Proust was an astute observer of the way in which new media and communication technologies produced this experience of internal distance. In The Guermantes Way, published in 1920 and 1921, for example, the narrator, Marcel, is thrown by his first telephone conversation with his beloved grandmother, as the 'tiny' and 'abstract' sound of her voice, divorced from her face and her physical presence, is translated into pure signal.

It is she, it is her voice that is speaking, that is there. But how far away it is!...

Many were the times, as I listened thus without seeing her who spoke to me from so far away, when it seemed to me that the voice was crying to me from the depths out of which one does not rise again...for always until then, every time that my grandmother had talked to me, I had been accustomed to follow what she said on the open score of her face, in which the eyes figured so largely; but her voice itself I was hearing that afternoon for the first time.

For Marcel, the uncanny experience of hearing this disembodied voice acts as an intimation of mortality, accentuating as it does the finitude of the body.

'Granny!' I cried to her, 'Granny!' and I longed to kiss her, but I had beside me only the voice, a phantom as impalpable as the one that would perhaps come back to visit me when my grandmother was dead. 'Speak to me!' But then, suddenly, I ceased to hear the voice, and was left even more alone...It seemed to me as though it was already a beloved ghost that I had allowed to lose herself in the ghostly world, and, standing 
alone before the instrument, I went on vainly repeating: 'Granny! Granny!' as Orpheus, left alone, repeats the name of his dead wife. ${ }^{12}$

The uncertain borderline between life and death also provokes Leopold Bloom to reflect on the uncanniness of another sound technology in James Joyce's Ulysses (1922). This time it is the gramophone, which Bloom speculates about as a means of recording and perpetuating the human voice.

How many! All these here once walked round Dublin. Faithful departed. As you are now so once were we.

Besides how could you remember everybody? Eyes, walk, voice. Well, the voice, yes: gramophone. Have a gramophone in every grave or keep it in the house. After dinner on a Sunday. Put on poor old greatgrandfather. Kraahraark! Hellohellohello amawfullyglad kraark awfullygladaseeagain hellohello amawf krpthsth. Remind you of the voice like the photograph reminds you of the face. Otherwise you couldn't remember the face after fifteen years, say. ${ }^{13}$

In The Wasteland, also published in 1922, T. S. Eliot invokes the more usual use of the gramophone as a music machine in the passage about a typist's casual sexual encounter with a 'small house agent's clerk...on whom assurance sits / As a silk hat on a Bradford millionaire'. Here it is not death that is summoned up but rather the deadening of affect in modern life. The recorded music in the typist's squalid flat conveys not just Eliot's disgust at her mechanical and disengaged coupling, but more generally his disdain for the dehumanised, automaton-like quality of contemporary culture.

She turns and looks a moment in the glass,

Hardly aware of her departed lover;

Her brain allows one half-formed thought to pass:

'Well now that's done: and I'm glad it's over.'

When lovely woman stoops to folly and

Paces about her room again, alone,

She smoothes her hair with automatic hand,

And puts a record on the gramophone.

A thread running through these various accounts of mechanically reproduced sound is their sensitivity to the double reality of an emerging post-war world. On the one hand, the noise of modern life and the technologies of sound reproduction are part of a changing external reality: Simmel's crystallised spirit, Musil's durable stuff or simply 'objectivity'. The other reality, no longer conceivable in terms of individual human qualities, is subjectivity mediated through mass-produced sounds and technologies that dislocate or subvert the familiar coordinates of space and time. This learned estrangement of the senses transmutes into a disturbing rhythm that is sometimes stultifying and sometimes 
febrile. This is the inner reality and rhythm of modern life lived to the tempo of jazz.

\section{The jazz age}

In 1931, F. Scott Fitzgerald reflected on the era that he had named 'the Jazz Age'. The word jazz, he observed, 'is associated with a state of nervous stimulation, not unlike that of big cities behind the lines of a war'. This is a useful reminder that jazz operated in the 1920s not just as a loose name for a wide variety of musical styles, but above all as a term of art. People were certainly hearing new kinds of popular music, in music halls and nightclubs and especially as recorded on disc and broadcast on the radio. But jazz above all provided a metonym for talking about the times, as well as a soundtrack to them. In 1924, for example, Irving Berlin, who would have been considered a jazz composer, compared the music to the 'rhythmic beat of our everyday lives'. 'Its swiftness is interpretive of our verve and speed and ceaseless activity. When commuters no longer rush for trains, when taxicabs pause at corners, when businessmen take afternoon siestas, then, perhaps, jazz will pass. ${ }^{14}$

Jazz was thus heard as the rhythm of modernity and as the noise of machinery. Jazz also mimicked the universal flow of capital and of commodities by spreading everywhere. A New York writer reported home from his world travels:

No sooner had I shaken off the dust of some city and slipped almost out of earshot of its jazz bands than zump-zump-zump, toodle-oodle-doo, right into another I went. Never was there a cessation of this universal potpourri of jazz. Each time I would discover it at a different stage of metamorphosis and sometimes hard to recognize, but unmistakably it was an attempt at jazz. ${ }^{15}$

At the same time, jazz was part of the polyglot cosmopolitanism of Europe's capitals. Langston Hughes was working as a dishwasher in Le Grand Duc nightclub in Paris when he wrote his poem Jazz Band in a Parisian Cabaret in 1924.

Play that thing, Jazz band! Play it for the lords and ladies, For the dukes and counts, For the whores and gigolos, For the American millionaires, And the school teachers Out for a spree. Play it, Jazz band! You know that tune That laughs and cries at the same time. You know it. May I? Mais oui. Mein Gott! Parece una rumba. Play, jazz band! You've got seven languages to speak in And then some, Even if you do come from Georgia. Can I come home wid yuh, sweetie? Sure. ${ }^{16}$

Although universal and cosmopolitan, jazz was also heard as specifically American and in some often vague way as black. Kurt Weill in 1926 was more musically precise than many of his contemporaries: 
The rhythm of our time is jazz. The Americanization of our whole external life, which is happening slowly but surely, finds its most peculiar outcome here. Unlike art music, dance music does not reflect the sense of towering personalities who stand above time, but rather reflects the instinct of the masses... Negro music, which constitutes the source of the jazz band, is full of complex rhythm, harmonic precision, and auditory and modulatory richness which our dance bands simply cannot achieve. ${ }^{17}$

Being heard as American and black, jazz embodied the very sound of the crisis as which modernity was experienced in Europe. As early as 1921, the Bloomsbury art critic Clive Bell hoped that the fad for jazz was passing, because it represented for him banal and immature tendencies in modernity rather than the critical edge of modernism that he saw in the paintings of Picasso, Braque and Derain. The Paris-based German commentator Ivan Goll also picked up on this anxiety, but with a greater degree of self-awareness. Like many people formed by the trauma of the war, he saw that the vogue for jazz and for primitivism generally signified a loss of confidence in European culture and the desperate desire for a new cultural authenticity. In his dispatches to Die literarische Welt from the cultural front, he alerted Berliners that Josephine Baker and the Revue nègre were on their way.

The Negroes are conquering Paris. They are conquering Berlin. They have already filled the whole continent with their howls, their laughter. And we are not shocked, we are not amazed: on the contrary, the old world calls on its failing strength to applaud them... One can only envy them, for this is life, sun, primeval forests, the singing of birds and the roar of a leopard, earth.

Goll was, however, alert to the parodic nature of much of La Revue nègre, and scoffed at the assumption that its version of jazz and black America had anything to do with Africa.

These Negroes come out of the darkest parts of New York. There they were disdained, outlawed; these beautiful women might have been rescued from a miserable ghetto. These magnificent limbs bathed in rinse water. They do not come from the primeval forests at all. We do not want to fool ourselves. But they are a new, unspoiled race.

As Goll continues, he articulates a characteristic 'cultural eugenics' - the idea that an exhausted and etiolated European culture needs reinvigoration by 'Negro' blood.

Their dancing comes out of their blood, their life... The main thing is the negro blood. Drops of it are falling on Europe - a land, long dry, that has almost ceased to breathe. Is this the cloud that looks so black on the 
horizon? A shimmering stream of fertility?...Do the negroes need us, or do we not rather need them?

Whereas Bell railed against jazz because it confounded hierarchies of aesthetic cultural value and threatened to make 'the coloured gentleman who leads the band at the Savoy' the ultimate arbiter of taste, Goll heard in the sound of jazz and saw in the movement of black bodies a grotesque image of the strength, authenticity and intensity of affect that had been damaged mortally by the Great War and that were being further undermined by the American culture of which commercial jazz was another product.

The musician Paul Stefan put this more programmatically in an editorial for the avant-garde music journal Anbruch in 1925.

For us, jazz means: a rebellion of the people's dulled instincts against a music without rhythm. A reflection of the times: chaos, machines, noise, the highest peak of intensity. The triumph of irony, of frivolity, the wrath of those who want to preserve good times. The overcoming of Biedermeyer hypocrisy. ${ }^{18}$

The impact of jazz on Europe in the 1920s was, of course, more complex and more nuanced than I have been able to convey here. I have simply sketched how and why jazz functioned as the sound of modernity, and how it helped to school an emerging mentality. This had more to do with the way the music was heard in Europe than with the reasons why it was created in America, although the imagined relationship between Europe and America was a significant part of it. The actual cultural significance and aesthetic value of jazz were always greater than its detractors feared and often less than its supporters hoped. It was not yet a music of conscious African-American self-expression: it was the sound of an ambivalence towards the fact of modernity, a representation of Benjamin's complex training of the senses but also a sometimes startlingly inventive commentary on it. ${ }^{19}$

\section{Sound of the city/dissonant modernism}

In 1922, John Cournos, a Russian-born Jewish American shuttling between New York and London, published a novel that attempted to capture the rhythms and dislocations of the modern metropolis. Babel is in large part a roman à clef that (rather like The Man Without Qualities) looks back from a post-war perspective to London in 1913. It starts with a reflection on the apparently universal spread of capitalism and mechanisation and their links to imperialism. The narrator, Gombarov, soon begins to question whether this universalism is desirable or sustainable. When he first arrives in London from New York, he is first struck by the distinctiveness of the city's sounds as he boards a bus at Victoria Station. In contrast with the angular, wiry abstraction of Musil's Viennese soundscape, Cournos creates something like a post-impressionist tone poem. 
Having left Westminster Cathedral behind, the red 'bus almost noiselessly glided on, cunningly brushing past other red 'buses, with a gondola-like grace which was incredible; at times no more than a hair's breadth separated them. And there was no sudden, sharp, shrieking noises of taxi-horns and overhead trains as in New York; but there was a trembling and a rumbling in the air, steady and constant, the even breathing of modern life over vast spaces. All the noises were swallowed up and became as one noise, vibrant like that of a ship's turbine, incessantly throbbing, reduced to normal pulsation, diffuse mellowness of a tone painting, in which conflicting colours take their place without quarrelling with one another, and none shrieking. This, Gombarov had time to observe before reaching the end of his journey, had its counterpart in the physical contours of the streets, which were curiously free from sharp abutting angles so characteristic of the streets of the New World. ${ }^{20}$

Sitting on the top deck of the bus, Gombarov begins to grasp the intimate dynamic between the standardisation of the external world and the atomisation of subjective life - again, a theme of Simmel's - as he notices the cosmopolitan entertainments on offer along the Charing Cross Road.

The soul of old England was left behind in Trafalgar Square; the 'bus rolled on through one of the corridors of the new England. Up Charing Cross Road, past a cinema house, announcing 'The Grim Avenger: A Thrilling Romance of Three Continents', past the Hippodrome, blazing with lights; past the buildings of new flats, utterly banal but for the curve of the old street; past a music hall, flaunting across its front the pirouetting figure of a Russian toe dancer on a coloured screen, while underneath, flashing for the world to see, letters of bright light proclaiming other attractions: a Cockney Comedian, a Spanish Tango Turn, a Swedish Acrobat Troupe, American Clog Dancers, an Argentine 'Stunt' Artist, Naughty Fifi the French Comic Chanteuse, and Mimi, her Eccentric Accompanist, and so on, and so on: 'How amazingly international!' mused Gombarov, and laughed to himself, as the after-thought struck him: 'And here am I, a Russo-American Jew, looking on!'

Was this chaos or unity? It was chaos, and had a unity after a fashion. It was the unity of a many-tuned medley, each tune of which maintained its entity, losing it only at the moment of embracing another tune; at best, it was the unity of ultra-modern music, shaped out of discords, beaten but not molten into a harmony. ${ }^{21}$

This play on musical chaos and unity to capture the social complexity of the modern metropolis and the subjective life of its citizens provides a suitable metaphor to draw together the collage of quotations through which I have tried 
to recapture what a European capital in the 1920s might have sounded like, and how that noise might have been heard. Without, I hope, conflating the question of sound with the question of music, I have tried to show how modern music, primarily jazz, not only formed part of the new soundscape but also tried to make sense (or at least art) of it.

Through this evocation, however, I have also been making an argument about the sensual, preconscious dimension to the way in which historical change is experienced. Mass industrial production, consumer culture, post-war reconstruction and adaptation, the rise of America, a faltering democratisation, media technologies - all these powerful forces, and more, were experienced and to some extent made sense of through the senses, including the sense of hearing. Meaning, it has been said, occurs when sound meets prejudice. ${ }^{22}$ 'Prejudice' is a nicely chosen word. Less technical than Raymond Williams' 'structure of feeling' or Pierre Bourdieu's 'habitus', it connotes something less definite and certainly less easily describable even than the shared stories, myths and images that constitute what we have come to think of as 'cultures'. It suggests something more visceral and more elusive than that: unspoken and even unthought frames of perception, intuition, expectation and constraint that are nonetheless saturated by memories, desires and fears. These frames - subject to the complex training of technology and objective culture - are the way we hear and see the world, and thus the way we live history.

I have tried to indicate how strange was the modern sensory world coming into being in the 1920s. Even as scientists tried to remove extraneous distractions from recorded sound, the imaginative space of everyday life was becoming increasingly and uncannily over-populated by mechanical sounds and disembodied voices. The virtualisation of modern existence-accelerated if not caused by media technologies - could well have contributed to a characteristically modern sense of placelessness and even homelessness. This nostalgia is captured in David Vogel's description of the look and sound of Vienna at dusk in his 1929 novel, Married Life.

In the mild spring air a pure, gentle stillness seemed to drop from the darkening sky. The deserted streets looked as if they had just been swept. The city was sinking into sleep in the orange glow of the streetlamps. From time to time, at increasing intervals, a tram split the silence like a nightmarish awakening. A distant train emitted a long, muffled hoot. And for a moment the imagination was captured by long journeys through the soundlessly breathing night, strange cities populated by millions of human beings. ${ }^{23}$ 


\section{ENDNOTES}

1 I use 'soundscape' in the sense defined by Emily Thompson: 'Like a landscape, a soundscape is simultaneously a physical environment and a way of perceiving that environment; it is both a world and a culture constructed to make sense of that world. The physical aspect of a soundscape consists not only of the sounds themselves, the waves of acoustical energy permeating the atmosphere in which people live, but also the material objects that create, and sometimes destroy, those sounds. A soundscape's cultural aspects incorporate scientific and aesthetic ways of listening, a listener's relationship to their environment, and the social circumstances that dictate who gets to hear what.' See Thompson, Emily 1988, The Soundscape of Modernity: Architectural Acoustics and the Culture of Listening in America, 1900-1933, MIT, Cambridge, pp. 1-2.

2 Musil, Robert 1995, The Man Without Qualities, trans. Sophie Wilkins, Alfred A. Knopf, New York, p. 3.

3 Ibid., p. 4.

4 'The individual has become a mere $\operatorname{cog}$ in an enormous organisation of things and powers which tear from his hands all progress, spirituality, and value in order to transform them from their subjective form into the form of a purely objective life. It needs merely to be pointed out that the metropolis is the genuine arena of this culture which outgrows all personal life. Here in buildings and educational institutions, in the wonders and comforts of space-conquering technology, in the formations of community life, and in the visible institutions of the state, is offered such an overwhelming fullness of crystallised and impersonal spirit that the personality, so to speak, cannot maintain itself under its impact.' Frisby, David and Mike Featherstone (eds) 1998, Simmel on Culture, Sage, London, p. 184.

5 There is a chicken-and-egg danger here, pointed out by Jonathan Sterne. Developing a genealogy that 're-places sound reproduction within the longer flow of sound history', he argues that it is less that technologies of sound reproduction as such created new ways of hearing than that social techniques of listening that emerged in the course of the nineteenth century determined the construction of sound reproduction as a practice. Sterne, Jonathan 2003, The Audible Past: Cultural Origins of Sound Reproduction, Duke University Press, Durham, pp. 95-106.

6 Thompson, Soundscape, p. 3.

7 Ehrenburg, Ilya 1976 [1929], The Life of the Automobile, Urizen Books, New York, pp. 22-3.

8 Quoted in Thompson, Soundscape, p. 320.

9 North, Michael 1999, Reading 1922: A Return to the Scene of the Modern, Oxford, New York, p. 16.

10 Ibid., pp. 15-16.

11 Ibid., p. 208; emphasis added.

12 Proust, Marcel 1968, Remembrance of Things Past, vol. 2, trans. C. K. Scott Moncrieff and Terence Kilmartin, Chatto \& Windus, London, pp. 135, 137. For an insightful discussion of the Proust and Joyce examples, see Danius, Sarah 2002, The Senses of Modernism: Technology, Perception and Aesthetics, Cornell University Press, Ithaca, on Proust: pp. 14-15.

13 Quoted in Danius, The Senses of Modernism, p. 182.

14 Quoted in Thompson, Soundscape, p. 144.

15 Burnet Hershey's article in New York Times Book Review and Magazine is quoted in Johnson, Bruce 2003, 'The jazz diaspora', in Mervyn Cooke and David Horn (eds), The Cambridge Companion to Jazz, Cambridge University Press, Cambridge, p. 34.

16 Quoted in Edwards, Brent Hayes 2003, The Practice of Diaspora: Literature, Translation and the Rise of Black Internationalism, Harvard University Press, Cambridge, Mass., p. 63.

17 Weill, Kurt 1995, 'Dance Music', in Anton Kaes, Martin Jay and Edward Dimendberg (eds), The Weimar Republic Sourcebook, University of California Press, Berkeley, p. 597 (originally in Der Deutsche Rundfunk, 4, 14 March 1926, pp. 732-3).

18 Quoted in Taylor-Jay, Claire 2004, The Artist-Operas of Pfitzner, Krenek and Hindemith: Politics and the Ideology of the Artist, Ashgate, Aldershot, p. 100.

19 See also Johnson, 'The jazz diaspora', p. 50: 'Louis Armstrong might have made music of the twentieth century, but it was not he who made it the music of the twentieth century - for that we have to go to culturally and geographically diasporic spaces, Whiteman and white men, American Jews like Gershwin, Anglo-European commentators and the fans, readers, and musicians who were in some ways guided by them. Especially in the 1920s, jazz was to a significant degree the invention of diasporic discourses and practices, of non-African-Americans.' 
Talking and Listening in the Age of Modernity

20 Cournos, John 1923, Babel, Heinemann, London, p. 70.

21 Ibid., pp. 73-4.

22 Johnson, James H. 1996, Listening in Paris: A Cultural History, University of California Press, Berkeley, p. 2. Johnson is paraphrasing Hans-Georg Gadamer.

23 Vogel, David 1989, Married Life, trans. Dalya Bilu, Grove Press, New York. pp. 29-30. 